\title{
Lessons Learned from a Pandemic: One Medical School's Response to COVID-19
}

Peter Gilbey ( $\nabla$ drpgilbey@gmail.com )

Azrieli School of Medicine, Bar-Ilan University, Israel

Lilach Malatskey

Azrieli School of Medicine, Bar-Ilan University, Israel

Nomy Dickman

Azrieli School of Medicine, Bar-Ilan University, Israel

Daniel Glikman

Azrieli School of Medicine, Bar-Ilan University, Israel

Amnon Albeck

Bar-llan University, Israel

Eric S. Shinwell

Azrieli School of Medicine, Bar-llan University, Israel

Johnny S. Younis

Azrieli School of Medicine, Bar-llan University, Israel

\section{Research Article}

Keywords: COVID-19, Undergraduate medical education, pre-clinical teaching, clinical teaching, online teaching

Posted Date: July 9th, 2020

DOI: https://doi.org/10.21203/rs.3.rs-40374/v1

License: (c) (1) This work is licensed under a Creative Commons Attribution 4.0 International License.

Read Full License 


\section{Abstract}

Background: The COVID-19 pandemic disrupted medical education. Social distancing prevented students from gathering in any setting. Teaching became less effective due to lack of staff, cancellation of procedures, transition to telehealth and shortages of personal protective equipment. Medical schools' responses to previous lockdowns are not well documented. On March $13^{\text {th }} 2020$, all universities in Israel were closed and a transition to online learning was implemented. All clinical rotations were temporarily suspended. We describe changes to teaching and learning during the pandemic, and the evaluation of these changes.

Methods: Several surveys were performed. Selected faculty members were asked to comment on the transition to online learning, and assess which practices could possibly be adopted for future use.

Results: Overall satisfaction with online learning was high. High satisfaction was also reported regarding the delivery of online lectures, efficient transition to online teaching, and the maintenance of academic excellence despite the challenges of COVID-19. Twenty-three percent of medical students preferred to continue exclusive online learning in the future. Forty-five percent advocated for blended learning, mainly online. Selected challenges and opportunities are discussed.

Conclusions: The rapid transition to online teaching and learning was successful. Lessons learned and recommendations for the future are presented.

\section{Background}

The emergence of the COVID-19 pandemic disrupted medical education and demanded intense and immediate attention from medical educators ${ }^{1-3}$.

Medical schools' responses to sudden lockdowns are not well documented in the literature, and there are few reports outlining the response to previous epidemics ${ }^{3}$. During the severe acute respiratory syndrome (SARS) outbreak in China (2003-2004) some Chinese medical schools officially cancelled formal teaching on wards and their exams were delayed, hindering the education of medical students ${ }^{4}$. Similarly, in Canada, the SARS restrictions led to the cessation of clinical clerkships and electives for students for up to 6 weeks ${ }^{5}$.

On March $13^{\text {th }} 2020$, all higher education institutes in Israel were closed and an immediate transition to online learning was effected. All clinical rotations at all medical schools were suspended. On March $17^{\text {th }}$ 2020, the Association of American Medical Colleges (AAMC) issued guidelines suggesting that medical schools support pausing clinical rotations for medical students ${ }^{6}$. On May $1^{\text {st }} 2020$, the Medical Schools Council (MSC) in the United Kingdom issued a statement on clinical placements in which it stated that the long term resilience of the health service relies on maintaining the number of new healthcare professionals able to join the NHS annually ${ }^{7}$. 
Flipped classroom teaching methods ${ }^{8-10}$, including Team-Based Learning (TBL) ${ }^{11}$ had been implemented in pre-clinical and clinical settings. However, the majority of pre-clinical teaching was still lecture-based.

The aim of this report is to describe the response of one medical school in the North of Israel to the COVID-19 pandemic, and to present the initial evaluation of the changes implemented, exploring lessons learned for the "day after".

\section{Changes in Pre-Clinical Teaching and Learning:}

An immediate transition to online teaching and learning was implemented. No lessons were cancelled, and all lectures were recorded and made available to students for personal study at their convenience. Intensive on-site technical support enabled this transition. When possible, curricular content that was planned for the current semester was postponed to a later date.

Participation in lectures, that had been mandatory, was made voluntary, although active participation was encouraged.

Existing communication avenues between students and faculty were reinforced. Course directors and faculty leadership made themselves available to student representatives whenever necessary.

Assessment of students was reconsidered in all pre-clinical courses. Technical solutions for the proctoring of students taking examinations at home were examined, but were deemed to be unacceptable. When possible, multiple-choice based examinations were replaced by oral examinations, essay questions or individual projects. Open-book, open-web examinations were considered in some cases, based on research demonstrating reduction of anxiety and deeper learning ${ }^{12}$. In these cases, students were required to sign a personal declaration regarding integrity and honesty in exams prior to each examination.

Small-group activities were adapted to online settings. All meetings with standardized patients were postponed, as were the demonstration and practice of physical examination.

Several issue remained unsolved. These include cadaver dissections in the anatomy course, which if necessary could be replaced by demonstrations in small groups and the use of technological solutions such as the 3-D anatomy software and hardware combination table, and objective structured clinical examinations (OSCE).

\section{Changes in Clinical Teaching and Learning:}

During suspension of clinical rotations, many students volunteered to participate in the National Coronavirus testing program. On April $19^{\text {th }} 2020$, an online clinical teaching program was initiated. 
Interactive online lectures, combining selected clinical cases, on a variety of major clinical issues, were offered to students in Internal Medicine, Obstetrics \& Gynecology, Family Medicine, Pediatrics, Psychiatry and General Surgery. These interactive lectures were recorded for future viewing. Second and fourth-year internal medicine students were taught together due to a shortage of qualified internal medicine teachers, who were appointed as first-line health providers for the COVID-19 patients.

\section{Methods}

In order to perform an initial evaluation of the satisfaction of students and faculty regarding the transition to online learning and the changes implemented with the outbreak of the COVID-19 pandemic, a number of online surveys were performed.

Bar-llan University performed a large-scale online survey examining the attitudes of all University students to online learning. The survey was developed for this study (see supplementary file). Medical students' evaluation of teaching surveys were adapted to include evaluation of online learning. The Bar-llan University Medical Students Union conducted an informal internal survey of students' satisfaction with online learning.

The Vice-Deans for pre-clinical and clinical studies, course directors, and the Chairs of Internal Medicine and Obstetrics \& Gynecology were asked to comment on the transition to online learning, and to assess which practices could possibly be adopted for future use.

All evaluations were conducted as part of routine teaching evaluation. They were not originally designed as research, and therefore no ethics committee approval was sought.

\section{Results}

\section{Students:}

During the last week of March 2020, The Bar-llan University conducted an online survey of all students currently actively studying at the university. A total of 2572 students responded to the survey for an overall response rate of $17.7 \%$. In the faculty of Medicine, 534 students were invited to participate in the survey. Of these, only 170 were actually engaged in online learning due to the fact that all clinical studies had been temporarily suspended. 56 students responded, for a response rate of $33 \%$. There is no available information regarding the perceptions of non-responders to the survey.

Among medical students, the overall satisfaction with online learning was 7.9/10. A mark of 8 or higher out of 10 was given by $66 \%$ of medical students regarding the technical quality of the online meetings, and by $55 \%$ of medical students regarding the delivery of online lectures. A mark of 8 or higher out of 10 was given to the university administration by $86 \%$ of medical students regarding a rapid and efficient transition to online teaching and learning, by $79 \%$ regarding attentiveness to the needs and requests of students, by $71 \%$ regarding the provision of full, clear and up-to-date information to students, and by $70 \%$ 
regarding the maintenance of academic excellence despite the challenges of COVID-19. $82 \%$ of medical students felt that they would successfully complete the semester.

Twenty-three percent of medical students participating in the survey preferred to continue exclusive online learning in the future. Forty-five percent advocated for blended learning, mixing limited frontal and mainly online learning while thirty percent advocated for blended learning with mainly frontal learning and some online components. Only two percent preferred full face to face frontal learning.

The Bar-Ilan University Medical Students Union reported that in the informal survey of their members the general feeling was that online teaching was well performed, in an atmosphere of ongoing improvement. The students stated that online learning caused feelings of isolation and lack of human contact.

The evaluation of teaching surveys in pre-clinical studies demonstrated a high level of satisfaction with online learning (4.1 out of 5 on a Likert scale of 1-5). In the written comments the students expressed satisfaction with the recording of lectures, and the possibility of viewing them at a later date. The students expressed hope that lectures would be recorded routinely in the future. Students stressed the appreciation of Faculty's determination that they benefit from the course despite the limitations. They stated that online learning does not seem to be universally accepted and is probably not right for all students.

Student evaluation of teaching surveys in Internal Medicine demonstrated a difference between students in different years of study. Students in their second year of clinical studies were less satisfied with online teaching. Their satisfaction with the subjects taught was 3.2 on a Likert scale of 1-5, with clinical cases presented 2.2 out of 5 , and with online teaching overall 2.9 out of 5 . However, students in their last year of clinical studies had higher levels of satisfaction. Their satisfaction with the subjects taught was 4.1 on a Likert scale of $1-5$, with clinical cases presented 3.1 out of 5 , and with online teaching overall 4.4 out of 5 .

Internal Medicine students commented that the heterogeneous population of second and fourth-year students learning together was detrimental to learning.

Student evaluation of teaching surveys in Obstetrics \& Gynecology demonstrated high satisfaction with online learning. Their satisfaction with the subjects taught was 4.3 on a Likert scale of 1-5, with clinical cases presented 3.4 out of 5 , and with online teaching overall 4.3 out of 5 .

In written comments students stated that there is nothing that can replace hands-on, bedside teaching.

Students expressed satisfaction with the combination of developing clinical cases in online lectures. There were comments expressing a feeling that the student-teacher interaction was limited in the online setting in comparison to conventional bedside clinical teaching.

Faculty: 
Pre-clinical course directors expressed high satisfaction with the transition to online teaching and learning. Online clinical lectures' attendance was $66 \%$ on average in Obstetrics and Gynecology, and $88 \%$ on average in Internal medicine. Most lecturers initially required on-site technical support, although, with time, experience was gained and less support was needed.

Lecturers expressed difficulty connecting with students in an online setting, and ensuring participation of less engaged students. The tendency of some students to deactivate the webcam during lectures added to the sensation of "talking to a blank screen". It seemed that most students preferred to ask questions via a chat function. However, lecturers found it difficult to react to the questions asked in the chat during the lecture.

Clinical department heads stressed that students in clinical rotations needed direct contact with patients, and that online teaching could never fully replace traditional bedside teaching.

However, department heads remarked on "the ease and simplicity" of online teaching. They stated the advantage of being able to recruit outstanding and experienced teachers for online lectures, and possibly to cooperate with other medical schools in the country, or even internationally.

Lecturers were dissatisfied with the mixture of internal medicine students from different years of study, and felt that it was not possible to adequately meet the needs of all students. It was found that students who were trying to avoid active participation found it easier to do so online in comparison to a traditional clinical rotation.

\section{Discussion}

The aim of this preliminary study was to describe the response of one medical school to the outbreak of the COVID-19 pandemic, to document the changes in pre-clinical and clinical teaching and learning, and to present an initial evaluation of these changes.

In this study, we have examined the trainees' and trainers' reaction to online teaching and learning. We have described the improvement in online teaching and learning skills and the presumed change in attitudes. We have no data from our medical school regarding original attitudes toward online teaching and learning, but the literature describes obstacles to online teaching ${ }^{13,14}$, and we presume that these were also the attitudes in our school. Regarding academic achievements after online learning, it is difficult to compare non-proctored examination results with previous proctored examination results. However, students' results during this period were similar to normal years and in some cases were even marginally better. As to on-the-job behavior regarding online teaching and learning, there was no choice but to change under the unique circumstances that evolved. However, it does seem that both lecturers and students would, without doubt, like to see online teaching combined in faculty practices in the future.

It is clear that the transition to online teaching and learning mandates more thorough and in-depth evaluation in the future. However, we believe that due to the lack of literature describing these issues, and 
the unusual circumstances in which medical schools all over the world found themselves, there is much to be learned from the initial experiences of medical schools.

All in all, the transition to online teaching and learning was seamless, and was met with almost universal satisfaction. A transition that under normal circumstances might have taken years of planning, preparation and careful and gradual implementation, was brought about almost immediately. This presents a unique opportunity to retain some or even most of these practices in the future.

Open avenues of communication between students and faculty were found to be essential during these times of uncertainty. The students expressed high levels of satisfaction with the frequent meetings between student representatives and faculty, and with the way students' concerns were heard and addressed.

Sixty-eight percent of the pre-clinical medical students participating in the Bar-llan University online learning survey supported either exclusive online teaching or blended teaching combining mainly online teaching and less face-to-face teaching in the future. To our knowledge, there are no similar results in the medical literature for comparison, but these are, in the authors' opinion, impressive and surprising results. Regarding students in clinical years, although a high satisfaction rate was demonstrated during online courses, it should be emphasized that online teaching was the only option available at that time.

Studies have shown that students consider lecture recordings beneficial, and they use the recordings primarily to review the lecture at their convenience. While faculty members reported concerns with decreased attendance, few students reported using recordings as an alternative to class attendance ${ }^{15,16}$. In this study, students and faculty expressed satisfaction with the possibility of reviewing lectures at a later stage, in a place and time of the students' choosing, at a desired pace, and as many times as necessary. There was wide agreement that lecture recording should be adopted in the future.

In times of crisis, with limitations on attendance and learning, some curricular content can be postponed or cancelled.

No significant decline in online classroom attendance was seen. Compulsory attendance has been shown to improve attendance rates but the range and mean marks of absentee students was similar to the class as a whole ${ }^{17,18}$. Some students may learn as well or better outside the classroom than in it. Making lecture attendance mandatory is the individual decision of each medical school. Online lectures the potential to eliminate wasted travel time of outside lecturers, who until now had had to travel to the campus, which is relatively remote. In all small-group activities, clinical skills workshops, simulations, anatomy dissections and laboratories attendance should remain compulsory.

Our Faculty, being at a peripheral geographic location and societal position, has stressed physical attendance and participation. This has been a disincentive to some excellent students whose priority is a central location. Now that we have strong preliminary evidence for the success of on-line learning for 
certain major components of medical education, it is unclear whether we can maintain insistence on physical presence in pre-clinical course studies.

Students expressed satisfaction with interactive online lectures with developing clinical cases, although the mixture of students from different years of study in the same online lecture was found to adversely affect the ability of faculty to meet the needs of all students. It is possible that some clinical experience is required in order to benefit from online clinical lectures.

Some lecturers felt isolated from students during online lectures and found that interaction was limited. This feeling was exacerbated by students deactivating webcams during lectures. At a later stage, the use of a webcam was made compulsory in all online small-group activities.

Assessment of students' learning presented a special challenge. Research has shown that assessment is one of the most powerful determinants of student learning behaviors ${ }^{19-21}$, and assessment has been described as "the tail that wags the curriculum dog" 22. With the outbreak of COVID-19, a review of the assessment methods of all current courses was conducted. In the case of long-term limitations, especially with high-stakes examinations, students would have to be brought into the faculty in small groups for proctored examinations.

Small-group activities can be continued online, although there are some significant limitations. The demonstration and practice of physical examination and communication skills was severely limited. No anatomy dissections or OSCEs were planned during the initial stages of the pandemic. In the case of long-term limitations, students would have to attend small-group lessons while maintaining social distancing. This could potentially cause significant difficulties, especially with limited availability of clinical teachers.

There was wide agreement that online lectures cannot replace traditional clinical rotations. This was stated repeatedly by both students and faculty at all levels. Online lectures with developing clinical cases were seen as a partial and temporary measure. The authors believe that, in the spirit of the declaration of the Medical Schools Council in the UK ${ }^{7}$, in the case of a long-term pandemic, clinical students will have to be designated essential workers, and clinical teaching an essential function of physicians. This is also a unique learning opportunity for medical students, and a vital contribution to the formation of professional identity.

Limited availability of clinical learning sites should lead to careful preference of more essential rotations, for example in the case of final year students who are supposed to graduate in the near future. During clinical rotations, students can be divided into smaller groups or capsules, with each capsule attending the clinical ward at different times of the day or different days of the week.

This preliminary study has some potential limitations. The response rate of medical students to online surveys was not high. We have no data regarding the population that elected not to participate in the 
surveys. Results represent the experience of one medical school in one country, and therefore might not be generalizable to a wider population.

\section{Conclusions}

We have described the response of one medical school in Israel to the outbreak of the COVID-19 pandemic. We have documented the changes in pre-clinical and clinical teaching and learning, and presented an initial evaluation of these changes.

All in all, the transition to online teaching and learning was successful and well-received by faculty and students alike.

We hope that our conclusions and thoughts regarding the future will be useful to other medical schools globally, contemplating what to take from this tragic experience in order to improve medical education in the future. We have no doubt that the COVID-19 pandemic has presented a unique and genuine opportunity to change teaching and learning in the health professions for the better.

\section{Abbreviations}

COVID-19: Coronavirus Disease-19

SARS: Severe Acute Respiratory Syndrome

AAMC: Association of American Medical Colleges

MSC: Medical Schools Council

NHS: National Health Service

TBL: Team Based Learning

OSCE: Objective Structured Clinical Examination

UK: United Kingdom

\section{Declarations}

\section{Consent to Participate}

Participation was voluntary and all participants consented to participate.

\section{Ethics approval and consent to participate:}

All evaluations were conducted as part of routine teaching evaluation. They were not originally designed as research, and therefore no ethics committee approval was sought. 


\section{Consent for publication:}

Not applicable

\section{Availability of data and materials:}

The datasets used and/or analysed during the current study are available from the corresponding author on reasonable request.

\section{Competing interests:}

The authors declare that they have no competing interests

\section{Funding:}

No funding was received

\section{Authors' contributions:}

PG made a substantial contribution to the design of the work and analysis of data, drafted the work and approved the version to be published.

LM made a substantial contribution to the design of the work and acquisition and analysis of data, revised the work critically for important intellectual content and approved the version to be published.

ND made a substantial contribution to the design of the work and acquisition and analysis of data, revised the work critically for important intellectual content and approved the version to be published.

DG made a substantial contribution to the design of the work and acquisition and analysis of data, revised the work critically for important intellectual content and approved the version to be published.

AA made a substantial contribution to the design of the work and acquisition and analysis of data, revised the work critically for important intellectual content and approved the version to be published.

ESS made a substantial contribution to the design of the work and acquisition and analysis of data, revised the work critically for important intellectual content and approved the version to be published.

JSY made a substantial contribution to the conception and design of the work and acquisition and analysis of data, revised the work critically for important intellectual content and approved the version to be published.

All authors agree to be accountable for all aspects of the work in ensuring that questions related to the accuracy or integrity of any part of the work are appropriately investigated and resolved.

\section{Acknowledgements:}


The authors wish to thank Prof. Karl Scorecki, Faculty Dean, for his in-depth review of the manuscript and for his support.

\section{References}

1. Rose S. Medical Student Education in the Time of COVID-19. Jama. 2020:9-10. doi:10.1001/jama.2020.5227

2. Goh P-S, Sandars J. A vision of the use of technology in medical education after the COVID-19 pandemic. MedEdPublish. 2020;9(1):1-8. doi:10.15694/mep.2020.000049.1

3. Taha MH, Abdalla ME, Wadi M, Khalafalla H. Curriculum delivery in Medical Education during an emergency: A guide based on the responses to the COVID-19 pandemic. MedEdPublish. 2020;9(1):112. doi:10.15694/mep.2020.000069.1

4. Patil NG, Chan Ho Yan Y. SARS and its effect on medical education in Hong Kong. Med Educ. 2003;37(12):1127-1128. doi:10.1046/j.1365-2923.2003.01723.x

5. Clark J. Fear of SARS thwarts medical education in Toronto. BMJ. 2003;326(7393).

6. AAMC. Important Guidance for Medical Students on Clinical Rotations During the Coronavirus (COVID-19) Outbreak | AAMC. https://www.aamc.org/news-insights/press-releases/importantguidance-medical-students-clinical-rotations-during-coronavirus-covid-19-outbreak. Published 2020. Accessed May 16, 2020.

7. MSC. Statement onclinical placements. https://www.medschools.ac.uk/media/2646/statement-onclinical-placements.pdf. Published 2020. Accessed May 16, 2020.

8. Prober CG, Heath C. Becoming a physician: Lecture halls without lectures - A proposal for medical education. N Engl J Med. 2012;366(18):1657-1659. doi:10.1056/NEJMp1202451

9. Ramnanan CJ, Pound LD. Advances in Medical Education and Practice Dovepress Advances in medical education and practice: student perceptions of the flipped classroom. Adv Med Educ Pract. 2017;8:63-73. doi:10.2147/AMEP.S109037

10. Hew KF, Lo CK. Flipped classroom improves student learning in health professions education: $A$ meta-analysis. BMC Med Educ. 2018;18(1). doi:10.1186/s12909-018-1144-z

11. Michaelsen LK. Team-Based Learning for Health Professions Education: A Guide to Using Small Groups for Improving Learning. 1st ed. (L. Michaelsen, D. Parmelee, K. McMahon \& RL, ed.). Sterling, Virginia,US: Stylus; 2008.

12. Myyry $L$, Joutsenvirta T. Open-book, open-web online examinations: Developing examination practices to support university students' learning and self-efficacy. Act Learn High Educ. 2015;16(2):119-132. doi:10.1177/1469787415574053

13. O'Doherty D, Dromey M, Lougheed J, Hannigan A, Last J, McGrath D. Barriers and solutions to online learning in medical education - an integrative review. BMC Med Educ. 2018;18(1):130. doi:10.1186/s12909-018-1240-0 
14. Maggio LA, Daley BJ, Pratt DD, Torre DM. Honoring thyself in the transition to online teaching. Acad Med. 2018;93(8):1129-1134. doi:10.1097/ACM.0000000000002285

15. Maynor LM, Landis Barrickman A, Stamatakis MK, Elliott DP. Student and faculty perceptions of lecture recording in a doctor of pharmacy curriculum. Am J Pharm Educ. 2013;77(8):1-7. doi:10.5688/ajpe778165

16. Hussain A, Tabrez E, Basu A, D'Silva CSM. Medical Students' Perception of the Usage of Lecture Recording Software. Cureus. 2018;10(7). doi:10.7759/cureus.2963

17. Luder A. Should Medical Student Participation in Lectures be Compulsory? Harefuah (Hebrew). 2016;155(4):223-225.

18. Shmuel Reis. The Discussion about Lectures in Medical Education and the Question of Compulsory Participation - The Current Situation. Harefuah (Hebrew). 2016;155(4):226-228. doi:10.3109/0142159X.2011.613498.

19. Fraser BJ IAn. O. Identifying the Salient Facets of a Model of Student Learning: A Synthesis of Meta Analyses. Int J Educ Res. 1987;11(2):187-212.

20. Boud D. Developing Student Autonomy in Learning. In: 2nd ed. New York, NY: Nichols; 1988. doi:https://doi.org/10.4324/9780203059036

21. Brown S, Glasner A. Assessment Matters in Higher Education: Choosing and Using Diverse Approaches. 1st ed. Buckingham: The society for research into higher education; 1999.

22. Hargreaves A, Ontario Institute for Studies in Education. Curriculum and Assessment Reform. Toronto, Ontario: OISE Press; 1989.

\section{Supplementary Files}

This is a list of supplementary files associated with this preprint. Click to download.

- BarllanQuestionnaire.docx 